\title{
EduCAÇÃo SUPERIOR bILÍNGUE PARA SURdOS: O SENTIDO dA POLÍTICA INCLUSIVA COMO ESPAÇO DA LIBERDADE: PRIMEIRAS APROXIMAÇÕES
}

\author{
BILINGUAL UNIVERSITY LEVEL EDUCATION FOR THE DEAF - UNDERSTANDING
}

INCLUSIVE POLICIES AS A SPACE FOR FREEDOM: FIRST APPROACHES

MoniqueFRANCO${ }^{1}$

RESUM O : este trabal ho tem como objetivo apresentar um ensaio acerca da experiência em curso do Instituto N acional de Surdos (INES), na implantação do Instituto Superior Bilíngue de Educação (ISBE). O diálogo com Hannah A rendt ea concepção de política como espaço da liberdade consubstanciam esta reflexão. Inicialmente, o recente contexto educacional dos surdos, com a aprovação do Decreto n.05.626/ 2005, que regulamenta a Lei n.ำ 10.436/2002, que oficializa a Língua Brasileira deSinais (LIBRAS), écolocado em cena. Em seguida, traçamse os elementos constitutivos básicos da recente construção da experiência deensino superior bilíngueno INES/ ISBE, com o curso de Pedagogia e os principais entraves a sua implantação. À guisa de reflexões finais, pretendese indicar o sentido da política inclusiva no contexto de uma Política Cultural Bilíngue, enquanto abertura histórica de sentido possa representar um ensaio à liberdade.

PA LA V RA S-CH A VE: ensino superior bilíngüe; políticas linguísticas; inclusão; Educação Especial

\begin{abstract}
A BSTRACT: this study aims to present an essay about the current experience of implanting the Bilingual Higher Education Institute- ISBE at the N ational Institutefor theEducation of the Deaf - INES. Two factors substantiate this reflection: the dial ogue with $\mathrm{H}$ anna A rendt and the conception of politics as a space for freedom. Initially, the scene is set by the current context for deaf education, after the Decree number 5626/2005, that regulates federal law number 10436, which rules on Brazilian Sign Language- LIBRAS. N ext, wetrace the basic elements that have constituted the recent construction of bilingual teaching experience at INES/ ISBE, with the Bachelor in Education and the main barriers that have been faced. In our closing reflections, we intend to discuss the meaning of inclusive policies within the context of Bilingual Cultural Policies, whereby the historical opening of this course may represent an attempt at greater freedom.
\end{abstract}

KEYWO RD S: bilingual higher education; linguistic policies; inclusion; Special Education.

\footnotetext{
${ }^{1}$ Historiadora (PUC/ RJ), M estre em Educação (PPGED/ UFRJ) e Doutora em Comunicação e Cultura (ECO/ UFRJ). Professora A djunta do Departamento deEducação da Faculdade de Formação deProfessores da Universidade do Estado do Rio de Janeiro (FFP/ UERJ). Membro da Comissão Executiva e Editorial do Instituto Nacional deEducação deSurdos (INES/ MEC). mfranco@uerj.br
} 


\title{
1 INTRODUÇÃo
}

\author{
O sentido da política é a liberdade. \\ (Hannah A rendt. 0 que é política?) \\ Quando se quer estudar os homens, é necessário olhar bem de \\ perto. Mas, para estudar o homem é preciso aprender a levar \\ longe este ol har. É necessário antes de mais nada, observar as \\ diferenças para então descobrir as propriedades. \\ (J.J. Rousseau. Essai sur I'origine de langues, cap. VIII)
}

\section{SURdeZ E EdUCAÇão SUPERIOR: QUE ESPAÇO É ESSE?}

O processo da inclusão educacional e social de portadores de necessidades especiais, de minorias étnicas e/ ou identitárias se intensificou nos últimos anos. Completados dez anos da nova Lei deDiretrizes eBases da Educação Brasileira (LDB 9.394/ 96), ações concretas passaram a ser implantadas, ainda que as condições de possibilidade de execução e de absorção de uma nova real idade fossem, de fato, estabelecidas.

O fato é que se pode identificar um processo de crescente visibilidade deindivíduos que anteriormenteestavam localizados à margem do processo social. Potencializados, esses indivíduos são objeto de políticas públicas, ganham notoriedadena mídia e passam a ocupar, paulati namente, o espaço do exercício da diferença, criando demandas e deixando transparecer a gama de enfrentamentos ainda necessários à perspectiva da inclusão como espaço da liberdade.

No caso da comunidadesurda, não poderia ser diferente. Aqueles que ao longo de séculos tiveram seu processo de comunicação oprimido e sua língua, muitas vezes, proibida de ser expressa, ganham o direito de serem educados a partir dessa língua, agora reconhecida eoficializada como uma expressão linguística alternativa.

No Brasil, o Decreto №. 5.626, de dezembro de 2005, que regulamenta a Lei n.⒑436, deabril de2002, que oficializa a Língua Brasileira deSinais (LIBRAS)², aparece como condição de possibilidade de uma política linguística para a comunidadesurda, mas sua implantação expressa, ainda, marcadas ambiguidades.

Em síntese, a nova legislação prevêinúmeros dispositivos que, ao longo dos próximos dez anos, objetivam oportunizar a inclusão social do surdo,

\footnotetext{
2 Estudos indicam que, no Brasil, falam-se cerca de 200 línguas tradicionais de comunidades estabelecidas no próprio território. Existem ainda 180 línguas indígenas faladas em todo o País, principal mentenas regiões N orte e Centro-Oeste. Coexistem, além do português, línguas indígenas, línguas de imigrantes e duas línguas de sinais registradas: a LIBRAS, utilizada nos grandes centros urbanos pela comunidade surda, e a Língua de Sinais Urubu-Kaapor, desenvolvida na comunidade indígena de mesmo nome no Maranhão. Disponível em: 〈http:/ / www.sil.org/ américas/ brasil/ PUBLCNS/ LING/ UKSgnL.pdf>. Último acesso em fevereiro de 2007.
} 
reconhecendo, para esse segmento, a LIBRAS como primeira língua e/ ou língua de instrução.

Dentre as ações propostas, o Decreto no. 5.626 prevêa inclusão de uma disciplina de LIBRAS em todos os cursos de licenciaturas no Brasil, com vistas a instrumentalizar professores e professoras acerca dessa modal idade decomunicação e, com isso, proporcionar uma melhora do reconhecimento e relacionamento professor ouvinte-aluno surdo. Está claro para os formuladores da legislação que tal disciplina não formará professores ouvintes proficientes em LIBRAS, mas trará a sua formação a possibilidade de desestigmatizar padrões preestabelecidos etrazer essa nova realidade ao diál ogo com o cotidiano escolar.

Por outro lado, o Decreto possibilita, ainda, a criação de cursos superiores com vistas a atender a comunidadesurda. A princípio, dois cursos ficam claramente expressos: a licenciatura Letras/ LIBRA Sou Letras-LIBRAS/ Português. O objetivo éformar professores para lecionar a LIBRA S desde a 5. ${ }^{\text {a }}$ série do ensino fundamental até a educação superior. Para a modalidade de educação infantil e séries iniciais do ensino fundamental, o Decreto prevê a criação de cursos de pedagogia bilíngue LIBRAS/ Português. Ainda no âmbito do ensino superior, o Decreto indica a criação de cursos de graduação e pós-graduação para formação detradutores-intérpretes de LIBRAS/ Português, Português/ LIBRAS. Também na formação dos fonoaudiólogos, profissionais que atuam diretamente com questões relacionadas à linguagem, o Decreto aponta para a inclusão da LIBRAS como disciplina obrigatória, contemplando, por exemplo, problemas típicos dos surdos que, de forma recorrente, apresentam desvios de linguagem, como afasias e aquisição tardia de comunicação.

Por fim, o reconhecimento oficial da LIBRAS assegura aos surdos a presença de intérpretes em espaços formais e instituições em geral, e tornará obrigatórios os requi sitos de acessibilidade à comunicação, previstos pelo Decreto n- 5.626, de dezembro de 2005, para as pessoas surdas, nas instituições federais de ensino enas instituições privadas deensino superior, encaminhando em seu capítulo III, item 2, a necessidade da formação do intérprete de Libras.

Todavia, todas essas ações trazem à cena uma série de enfrentamentos. Se, por um lado, podem representar um esforço na luta do processo de inclusão educacional e social desse segmento minoritário linguístico, podem revelar, também, elementos ainda vinculados a uma educação assimilacionista dos padrões dominantes, distante do efetivo exercício da alteridade necessária à prática da diferença, já que sua prática se distancia dos discursos propalados. Pior, podem indicar a expressão de uma política inclusiva homogeneizantee, portanto, distante dos pressupostos inerentes a uma prática política comprometida com a liberdade e autonomia dos sujeitos, nos moldes pensados pela filósofa Hannah A rendt.

Segundo a mesma autora, a política trata da convivência entrediferentes (ARENDT, 2006, p.21) e deve, assim, organizar e regular o convívio de diferentes, não de iguais. 


\begin{abstract}
Distinguindo-se da interpretação geral comum do homem enquanto um zoon politikon (A ristóteles), em consequência da qual o político seria inerente ao ser humano, A rendt acentua que a política surge não no homem, mas sim entre os homens, que a liberdade e a espontaneidade dos diferentes homens são pressupostos necessários para o surgi mento de um espaço entre homens, onde só então se torna possível a política, a verdadeira política (SONTHEIMER, 2006, p. 8).
\end{abstract}

A autora argumenta que a experiência de nossa era, sobretudo com as diferentes formas de regimes totalitários, fez declinar o sentido da política. Sem deixar de sinalizar o atravessamento das relações de poder no espaço político, a compreensão da política de Hannah A rendt está para além das instâncias burocráticas e/ ou meramentediscursivas. Tendo como ponto de partida a clássica experiência grega na antiga polis, o pensamento da autora, mesmo com o declínio dos regimes totalitários, ainda pode contribuir com reflexões que tenham como premissa a investigação de processos nos quais a prática política seja capaz de instaurar percursos emancipatórios, de inverter lógicas colonizadoras e de fazer emergir o diálogo das diferenças.

É neste sentido que o pensamento da autora consubstancia as reflexões desta investigação, uma vez que as atuais políticas inclusivas revelam intenções nem sempre concretizadas, seja pelo fato de que já surgem colonizadas, seja pelo fato de que a ordem do discurso pode desenhar aparências estáveis, como se completas.

Hoje o campo da Educação Inclusiva, que engloba a educação para portadores de necessidades educativas especiais, compartilha, de forma cada vez mais clara, com a definição de uma educação bilíngue para surdos, como um reconhecimento político da surdez como diferença.

\title{
Relembrando Skliar:
}

Essa definição, ainda que imprecisa, sugere quea educação bilíngüe para surdos éalgo mais do queo domínio, em al gum nível, de duas línguas. Se a tendência contemporânea é fugir - intencional e/ ou ingenuamente - de toda discussão que exceda o plano estrito das línguas na educação de surdos, corre-se o risco de transformar a proposta bilíngüe em mais um dispositivo pedagógico "especial", em mais uma grande narrativa educacional, em mais uma utopia a ser rapidamente abandonada. Em síntese: a educação bilíngüe pode-se transformar numa "neo-metodologia" colonialista, positivista, a-histórica e despolitizada. (SKLIAR, 1999, p. 07)

Desta forma, o sentido da política como prática da liberdadeseexpressa no âmbito da educação de surdos quando diz o autor:

Discutir a educação bilíngüe numa dimensão política assumeum duplo valor: o "político" como construção histórica, cultural esocial, eo "político" entendido como as relações de poder e conhecimento que atravessam e delimitam a proposta e o processo educacional (SKLIAR, 1999, p.07) 
É no bojo desse processo que se deu início ao processo análise da implantação do Instituto Superior Bilíngue de Educação (ISBE), do Instituto Nacional de Educação de Surdos (INES), agora apresentado à reflexão e debate.

É importante salientar que o ensino bilíngue para surdos, em que a LIBRAS é a língua de instrução (L1) e o português étratado como segunda língua (L2), possui peculiaridades que dependem da localização das diferentes modal idades deensino ofereci das aos estudantes surdos ao l ongo desua trajetória escolar. O Ensino Superior, reunindo estudantes surdos e ouvintes, é uma experiência inovadora, pode-se dizer em todo o mundo, justificando-se, assim, a pertinência de pesquisas na área. ${ }^{3}$

A metodologia utilizada contou, inicialmente, com revisão bibliográfica sobre o tema e análise documental. O acompanhamento das reuniões com os docentes efetivados completou o primeiro recorte agora apresentado.

\section{Desenvolvimento}

\subsection{ENSINO SUPERIOR BILÍNGUE PARA SURDOS: PRIMEIRAS APROXIMAÇõES}

Segundo consta em documentação oficial do INES, ${ }^{4}$ em 21 de outubro de 2004, o Instituto N acional de Educação de Surdos apresentou ao Ministério de Educação pedido de autorização de curso superior de Pedagogia na modalidade de licenciatura. O curso faz parte do PDI do INES, apresentado para o quadriênio 2004-2008. Todavia, o M inistério assinala a necessidade de o Curso de Pedagogia ser redimensionado para Curso Normal Superior, conforme os ainda vigentes Parecer CNE n. 133/ 2001 e Resolução CNE-CP n.ำ 1/ 2002.

Dessa forma, consta que, em 18 de agosto de 2005, foi autorizado o funcionamento do Curso Normal Superior, licenciatura, habilitações para o Magistério para os anos iniciais do ensino fundamental do INES.

O primeiro vestibular para ingresso no Curso foi realizado em 2006, quando começou a funcionar o Curso N ormal Superior Bilíngue do INES.

Ocorre que, com a homologação, em 15 de maio de 2006, das novas Diretrizes N acionais para os Cursos de Pedagogia, a Direção do INES estabeleceu em setembro uma comissão para analisar e propor a viabilidade da opção de se transformar o Curso Normal Superior do INES em Curso de Pedagogia.

\footnotetext{
3 Tem-se registro de que o Japão desenvolve, no âmbito do ensino tecnológico, experiência similar. A Escola Superior de Saúde da Universidade de A veiro (ESSUA), Portugal, também registra uma experiência no âmbito do ensino superior para surdos. Já a Universidade de Gallaudet, em Washington, D.C., é uma instituição de educação superior voltada para cidadãos surdos ou com dificuldades de audição, dos Estados Unidos e do mundo.

${ }^{4}$ Projeto do Curso Bilíngüe de Pedagogia. DEZ 2006, mimeo.
} 
O curso Normal Superior aprovado inicialmente possuía oito eixos norteadores, a saber: Reconstruindo a trajetória educativa; Construindo ol hares sobre o cotidiano escolar; A ssumin do estudos próprios da profissão docente; A profundando rel ações ensino-apren dizagem no trabal ho pedagógico; R edesenhando entendimentos no trabal ho pedagógico; Redesen hando enten dimentos edu cativos; delinean do propostas metodológicas; Reconstruindo a trajetória da formação; R ediscutindo propostas edu cativas emetodol ógicas, conforme apresentado em anexo. ${ }^{5}$ Tinha como objetivo geral formar professores para as séries iniciais e educação infantil em âmbito bilíngue.

Para a mudança, impunham-se à Comissão duas grandes tarefas. A primeira foi verificar, inicialmente, as demandas de alteração derivadas das diferenças de atribuições entre os concluintes do Curso N ormal Superior e os dos Cursos dePedagogia organizados pela Res. o. 01/ 2006. Em síntese, a carga horária de Prática de Ensino e Estágio Supervisionado (800 horas) e de A tividades Complementares ( 200 horas) foi reduzida, respectivamente para 300 e 100 horas. Essas 600 horas foram destinadas à oferta de disciplinas e atividades formativas para as novas atribuições do Graduado em Pedagogia, Licenciatura.

A segunda tarefa consistiu em adaptar a proposta deEixos Curriculares aos Núcleos de A tividades Formativas dispostos na Resolução (núcleo de estudos básicos; núcleo de aprofundamento ediversificação deestudos, núcleo deestudos integradores). ${ }^{6}$ Dessa forma os eixos foram reaglutinados em núcleos, conforme apresenta o anexo: ${ }^{7}$

1 - Núcleo de Estudo Bási cos (em cinza médio): Reconstruin do a traj etória educativa; Construindo ol hares sobre o cotidiano escolar; Problemáticas da profissão docente; Disciplinas de língua portuguesa (I A VII);

2- Núcleo de A profundamento e Diversificação de Estudos (em cinza escuro no mapeamento): A profundando relações en sino-apren dizagem no trabal ho pedagógico; Redesenhando entendimentos educativos; D elineando propostas metodológicas; reconstruindo a trajetória da formação; Rediscutindo propostas educativas e metodológicas;

3- Núcleo deEstudos Integradores (em cinza maisclaro no mapeamento): Estágios Supervisionados e Práticas; Tópicos avançados de ensino bilíngue.

Dentreas disposições cruciais do curso, pode-se destacar quea Língua Brasileira deSinais (LIBRAS) constitui a língua de instrução do Curso, enquanto a

\footnotetext{
${ }^{5}$ A nexo 1.

${ }^{6}$ Vale observar que o diálogo inicial para a montagem do mapeamento curricular proposto incluiu o Curso de Pedagogia da Universidade Federal de Pelotas/ RS, do Curso de Pedagogia da Faculdade de Educação da Baixada Fluminense da Universidade do Estado do Rio de Janeiro, do Curso de Pedagogia da Universidade Federal do Estado do Rio de Janeiro, bem como, das experiências do primeiro ano de funcionamento do Curso Normal Superior do INES.

${ }^{7}$ A nexo 2.
} 
Língua Portuguesa constará como disciplina obrigatória em sua particularizada modal idade escrita. Esta é uma experiência inédita até então no Brasil.

Por outro lado, por meio de processo seletivo próprio para ingresso na Educação Superior, em idêntica proporção podem ser admitidos candidatos surdos e não surdos que obrigatoriamente apresentem suficiente fluência em LIBRAS.

O documento indica, também, que, desde esse processo inicial e até o completo término das atividades didático-pedagógicas que lhe competem, o Curso conta com capacitados intérpretes de LIBRAS/ Língua Portuguesa.

Outra especificidadeimportantedo Curso éo fato dequeaulas edemais atividades devem estar a cargo de docentes com suficiente informação sobre características linguísticas próprias do campo da surdez. Além disso, o projeto prevê flexibilidade na correção de provas e/ ou trabalhos redigidos pelo discente surdo, quando serão considerados o aspecto semântico ea singularidadelinguística manifesta no nível formal de sua escrita. Para os surdos que possuam resíduos auditivos e os queiram utilizar, estão previstos equipamentos de amplificação sonora de uso coletivo.

\section{Conforme conta no Projeto do Curso:}

Mantidas tais perspectivas, este Curso objetiva assegurar uma qualificada formação bilíngüe (LIBRAS/ Língua Portuguesa) para pedagogos surdos enão surdos, de forma a torná-los agentes brasileiros multiplicadores também em docências da modalidade de "Curso Normal" própria do Ensino Médio; Contribuir para com (re)definições e implementações de uma qualificada política de formação de professores da Educação Infantil, dos A nos Iniciais do Ensino Fundamental contemplada também a EJA, e do Ensino Médio para disciplinas de cunho pedagógico; Formar pedagogos competentes e comprometidos com posicionamentos éticos, queenglobem pensamento crítico, reflexivo ecriativo, por meio da construção de conhecimentos teóricos, técnicos e práticos, cujas correspondentes ações sirvam como marca de excelência e referência no país (2006, p.14)

Também condizente com a política nacional de Educação vigente em nosso país, o Curso indica que egressos surdos poderão optar, pois, por trabalhar de forma integrada com intérpretes de LIBRAS/ Língua Portuguesa em quaisquer futuras atuações de cunho pedagógico que porventura assumam.

\section{Por outro lado:}

Deigual modo previamentemencionada, constitui uma das disposições cruciais deste Curso a de que, durante todo o seu transcorrer, serão respeitadas características semânticas edesingularidadelinguística comumenteencontradas no nível formal desuasescritas, demaneira queseforem posteriormentelotados em escolas regulares públicas, seja na Educação Infantil, seja nas Séries I niciais, incluindo-se a EJA, ou no Ensino Médio em docências de âmbito pedagógico, lotados nas instituições de Educação formal ou não formal os egressos surdos deverão estar igualmente livres para assumirem todas as atribuições que dispensem competências particularmenterelacionadas comensinos formalizados da modalidade escrita do nosso Português (idem, p.18). 
Esta especificidadeéextremamenteimportante, pois torna-secada vez mais visível, no bojo do processo de inclusão social no Brasil, que a população surda utiliza naturalmente a LIBRAS e enfrenta dificuldades linguísticas na aprendizagem e uso de línguas orais como a Língua Portuguesa.

O projeto aprovado em dezembro de 2006 pelo MEC aponta para uma interessante ousadia curricular. Possui a grande tarefa de representar, de fato, a possibilidade de exercício da diferença da comunidade surda brasileira e o compromisso de que futuras gerações de estudantes surdos poderão contar com escolas e professores, surdos e ouvintes, mais bem preparados.

Dessa forma, acompanhar a implantação do Projeto, do dia a dia do espaço escolar, suas realizações, tensões e ambiguidades, torna-se uma tarefa política, nos moldes pensados pela filósofa: "A política neste verdadeiro sentido aparece raramente na História” (ARENDT, 2006, p.56). Cabe a nós não deixar escapar.

\subsection{Políticas Inclusivas: eXercício da liberdade?}

Tendo como pano de fundo este cenário, abre-se um leque de desdobramentos, detensões advindas do processo deimplantação cuja investigação em curso se desenvolve.

Inicialmente, vale um mapeamento acerca da realidade discente.

O curso dePedagogia realiza em 2006 o seu primeiro vestibular eaprova sessenta estudantes. Com reserva de 50\% para estudantes surdos, esse número não se confirma, seja pela pouca procura do curso, ainda novo, por parte da comunidadesurda (etambém da ouvinte), seja pela baixa aprovação dos estudantes surdos no exame de vestibular.

Realizada internamente, a prova devestibular aplicada procurou seguir os mol des tradicionais de provas objetivas e uma redação. ${ }^{8} \mathrm{~N}$ ão houvea alternativa, agora recorrente de provas gravadas em LIBRAS, para os estudantes surdos. Por outro lado, como o curso tem a LIBRAS como língua de instrução, foi realizada uma prova, entreos ouvintes dassificados, de proficiência na língua. Aos candidatos surdos foi oferecido o apoio do intérprete.

Surpreendentemente, o número de ouvintes aprovados no exame de proficiência revelou uma primeira contradição: ou o exame foi extremamente rudimentar no que diz respeito à proficiência de ouvintes em LIBRAS ou temos

\footnotetext{
${ }^{8}$ Consta que a desclassificação foi aplicada apenas aos candidatos que zeraram alguma parte da prova. Os demais seguiram em ordem de classificação. Não foi possível realizar, ainda, uma análise da prova aplicada. 
muito mais fal antes de LIBRAS do que se poderia imaginar. ${ }^{9}$ Em contrapartida, os surdos ficaram em desvantagem. Das sessenta vagas oferecidas, apenas quatorze foram preenchidas por estudantes surdos, sendo que desse universo quatro trancaram ou abandonaram o curso numa proporção correspondente de sete estudantes ouvintes.

Essa mesma realidade se repetiu no segundo vestibular, em 2007. Sel ecionando candidatos já para o recém-aprovado curso de Pedagogia e com o acúmulo da experiência anterior, o curso, mais divulgado dentre a comunidade surda, passa a contar com um quantitativo de quatro alunos surdos no turno da tarde contra vinte eseis ouvintes. No período noturno, essa real idade seapresenta com oito estudantes surdos contra vinte e dois al unos ouvintes.

A conjuntura exposta apresenta, de início, al guns questionamentos. Os dados revelam queo curso possui um número muito mai or deouvintes do que de surdos. Para além de estatísticas formais, os números podem vir a indicar práticas e representações muito mais atreladas ao universo ouvinte do que do surdo. Com essas proporções fica difícil, por enquanto, considerar o curso bilíngue. Os motivos podem ser vários, reunidos ou isolados. O ensino formal - sobretudo no que diz respeito ao ensino médio, e mesmo às classes de pré-vestibular oferecidas pelo INES aos estudantes surdos - não estaria preparando os estudantes, ainda que sel ecionados, por um processo, tudo indica, atípico de vestibular? Por outro lado, poder-se-ia relacionar essa baixa procura ao fato de queaos surdos não interessaria o curso dePedagogia, usual mentetambém discriminado por estudantes ouvintes?

Outra questão relevantea ser observada resideno fato de que, segundo os resultados do vestibular de 2007, a maior média geral foi de um aluno surdo $(91,50)$. O mesmo fato também ocorreu nas duas maiores notas da prova deredação $(4,0) .{ }^{10} \mathrm{~N}$ as provas objetivas, a maior média isolada também foi de um candidato surdo (37,50). Em contrapartida, a pior média geral, bem como a pior nota na prova objetiva ederedação ficaram com os candidatos ouvintes, respectivamente $(48,50)$, $(14,25)$ e $(10,00)$. No caso da prova de LIBRAS, 10 candidatos surdos obtiveram a nota máxima $(4,0)$ tendo o mesmo fato ocorrido com 07 estudantes ouvintes. A pior nota de LIBRAS foi de um estudante ouvinte $(15,00)$ e entre os surdos, a de 23,00. Dois fatos podem ser considerados aqui. De um lado, o de a média total ser computada juntamente com a nota de proficiência em LIBRAS, o que daria um caráter totalmente diverso se a mesma fosse apenas classificatória. Por outro, as

\footnotetext{
${ }^{9}$ Tem-sea expectativa de que parte dessa procura é oriunda do Curso Básico de A quisição da Língua Brasileira de Sinais oferecido pelo próprio INES. Composto de quatro semestres letivos correspondentes a quatro níveis, o curso oferece a formação inicial em LIBRA S e conta atual mente com o expressivo número de quase 700 inscritos. Todavia, num primeiro levantamento, constatou-se que a procura pelo curso está local izada entre familiares desurdos, com baixo nível de escolaridade, emesmo estudantes sem o ensino médio completo, o que revela a impossibilidade de atrelar-se a demanda de ouvintes no ISEB a esse universo.

${ }_{10}$ Vale observar que a equipe que corrigiu as redações teve como critério, no caso de candidatos surdos, o reconhecimento da língua portuguesa como L2 (segunda língua).
} 
maiores notas isoladas são dos surdos (redação eobjetiva) eas piores, muito piores, são deouvintes. Isso leva ao questionamento: quem são esses estudantes queagora ingressam no Curso de Pedagogia? São surdos oriundos de famílias ouvintes, de famílias surdas, são oralizados, estudaram ou não no INES? E quem são esses estudantes ouvintes, despertados pelo interesse do ensino bilíngue? Por que obtiveram notas isoladas tão baixas?

Mas há um outro dado comparativo importante. Desde setembro de 2006 a Universidade Federal de Santa Catarina (UFSC), em parceria com outras sete instituições de ensino - Instituto Nacional de Educação de Surdos (INES/ RJ), Universidade de Brasília (UNB), Universidade de São Paulo (USP), Universidade Federal do A mazonas (UFAM), Universidade Federal do Ceará (UFC), UniversidadeFederal da Bahia (UFBA ) eCentro Federal deEnsino Tecnológico de Goiás (CEFET/ GO) - estimuladas pela recente aprovação da Lei de LIBRAS, mantém um curso de graduação a distância, em regimesemi presencial, em Letras/ Licenciatura com habilitação em Língua Brasileira de Sinais (LIBRAS). A nova lei criou uma grande demanda por profissionais com essa graduação. ${ }^{11}$ Ao todo, quinhentas vagas, sendo sessenta na UFSC e cinquenta e cinco em cada um dos pólos que integram a parceria. Desse montante, $70 \%$ foram reservados aos instrutores de LIBRAS anteriormente capacitados pelo $\mathrm{MEC}^{12}$ e $30 \%$ para surdos ou usuários de LIBRAS que já tenham concluído o ensino médio. ${ }^{13}$

O fato é que, mesmo tendo como finalidade ser um curso bilíngue, atendendo a surdos eouvintes proficientes em LIBRAS, as cinquenta ecinco vagas oferecidas no pólo do Rio de Janeiro, no INES, foram ocupadas por surdos (instrutores ou concluintes de ensino médio). A maior parte dos selecionados constitui-se de surdos que possuem uma inserção significativa na comunidadeejá atuam na área educacional. Usuários proficientes em LIBRAS, muitos já atuando de forma reconhecida como intérpretes, não al cançaram classificação. Terá sido o conteúdo da prova, a forma como foi aplicada? Não seria o caso de estabelecer cotas para ouvintes, como ocorre nas Universidades ou mesmo no próprio curso de Pedagogia do INES?

Tal constatação desautoriza, pelo menos parcialmente, de um lado, a noção de que não haveria surdos devidamente preparados para um exame de vestibular; e de outro, a idéia de que a baixa procura do curso de Pedagogia do INES por partedos surdos ocorreu por falta dedivulgação. Outra questão podeser

\footnotetext{
${ }^{11}$ Existem cerca de 170 mil surdos no Brasil, de acordo com o último Censo realizado, no ano de 2000.

${ }^{12}$ Em agosto de 2006, o Ministério da Educação lançou o PROLIBRAS, ExameN acional de Certificação de Proficiência em Língua Brasileira de Sinais e ao Exame Nacional de Certificação de Proficiência em Tradução e Interpretação da Libras/ Língua Portuguesa.

${ }^{13} \mathrm{O}$ candidato ao curso precisou demonstrar fluência em Libras, pois as provas foram aplicadas na língua de sinais, enquanto a compreensão de textos, em língua portuguesa. Foram 15 questões sobre conhecimentos gerais formuladas em Libras ecinco sobre conteúdos da língua portuguesa, formuladas em português. Para todos os conteúdos em língua portuguesa o exame contou com intérprete em Libras.
} 
colocada em pauta: o fato de o curso Letras/ LIBRAS ser a distância, viabilizando a continuidade praticamenteintegral dos estudantes nas suas atividades profissionais, teria contribuído com o interesse da comunidade surda? A modalidadea distância, com a maioria das aulas ministrada em língua de sinais gravada, facilitou a inserção da comunidade surda?

No que diz respeito à realidade docente, as contradições também são inúmeras. Da equipede dez professores substitutos contratados que iniciou o curso nenhum tivera contato com a Língua de Sinais tampouco acumulava alguma reflexão acerca da educação de surdos ou de ensino bilíngue. No final de 2006, 0 INES realizou seu primeiro concurso público para provimento de dez vagas. Dos candidatos aprovados, apenas uma professora, da área delinguística, é proficiente em LIBRAS. Os demais professores encontram-sefazendo um curso, oferecido pelo próprio INES, de aquisição da Língua Brasileira deSinais, cuja duração é de apenas dois anos, não garantindo, portanto, a proficiência adequada para lecionar, sobretudo temas e reflexões de nível superior.

Esse fato remete a um outro problema: a questão dos intérpretes. ${ }^{14}$ Segundo a CORDE, o intérprete deve ser um profissional bilíngue; reconhecido pelas associações e/ ou órgãos responsáveis; intérpreteenão explicador; habilitado na interpretação da língua oral, da língua de sinais, da língua escrita para a língua de sinais, e da língua de sinais para a língua oral (1996, p.08).

No ano de implantação do curso, o INES contava com um convênio com a Federação Nacional de Educação e Integração do Surdo (FENEIS) no encaminhamento de profissionais intérpretes para a Instituição como um todo. Mas esse número era insuficiente. O Colégio de A plicação, hoje com cerca de 570 alunos surdos matriculados, da educação precoce ao pré-vestibular, além deoutros atendimentos, conta com oito intérpretes ${ }^{15}$. O ISBE tem, em seus quadros, quatro intérpretes, queatuam, ou deveriam atuar, em pares derevezamento. Essenúmero,

\footnotetext{
${ }^{14} \mathrm{~A}$ presença do intérprete, na mediação entre surdos e ouvintes, deve ser tão antiga quanto a existência das pessoas surdas no mundo. A qui, no Brasil, temos notícia da convocação oficial deintérprete, por órgão judicial, no então Instituto N acional deSurdos Mudos, ainda no final do século XIX, conforme documentos existentes na biblioteca do INES. É com a FENEIS que a atuação profissional de intérpretes de língua de sinais tem seu início e se estabelece no Brasil. São os próprios surdos, que, não mais suportando o bloqueio da comunicação, a falta total de acesso às informações por total omissão dos órgãos governamentais, deflagram não só um movimento reivindicando o reconhecimento dessa atividade profissional, como também promovem o início desse trabal ho em todo o Brasil. A tualmente, a FEN EIS possui, em seu quadro funcional, profissionais intérpretes capacitados em cursos livres de curta duração, organizados e promovidos por ela mesma, em todos os Estados em que já implantou sua representação, contando, no momento, com uma dezena de regionais. E, através da Federação dos surdos, pessoas vêm atuando como intérpretes da Língua Brasileira de Sinais e conseguindo o reconhecimento evalor profissional por parte da comunidade ouvinte, que passou a val orizar ea solicitar esse trabal ho à FENEIS. Tal fato muda, total mente, o antigo cenário de atuação do intérprete, de caráter filantrópico, até então muito forte no imaginário da sociedade em geral, dos usuários surdos, bem como da própria pessoa que se propunha desempenhar essa função (Leite, 2004).

${ }^{15}$ Sabe-se quea partir de 2008 o ISEB passou a contar com um número maior de intérpretes, mais precisamente, dois para cada turma ( três turmas do período da tarde e três da noite, correspondendo, respectivamente ao 5o período do curso em vigor). Todavia optou-se por manter a informação do quadro inicial para registrar, sobretudo, o primeiro ano de implantação do curso.
} 
que já é insuficiente para a realidade das turmas hoje ativas no curso (duas no turno da tarde e duas no da noite), tende a se tornar impraticável num futuro próximo. ${ }^{16}$ Por outro lado, tudo indica que, partindo do pressuposto de que o curso tem a LIBRAS como língua de instrução, o uso do intérprete, pelo menos a médio ou longo prazo, não seria mais necessário.

Mas a questão dos intérpretes vai mais além. A pesar do PROLIBRAS, os conteúdos expressos nas diretrizes curriculares do curso possuem uma complexidade que indicaria uma melhor formação desses intérpretes, e mesmo um espaço reservado para um trabalho prévio entre esses profissionais e os professores, tirando dúvidas, esclarecendo conceitos etc. Esse momento não está previsto na carga horária dos intérpretes tampouco na dos professores.

\section{Segundo Quadros:}

A tualmente, esse intérprete ainda está em um processo de formação de identidade, já que sua organização enquanto profissional eformação acadêmica ainda não se consol idaram. O intérpretedeverá, ainda, ter conhecimento prévio de todos os assuntos de todas as disciplinas que fará a tradução simultânea, podendo atuar desde a educação infantil até o nível universitário e de pósgraduação, mas não poderá se confundir com o professor, queéo responsável pelo processo de avaliação dos al unos. (2002, p. 23)

Ou seja, está claro que a maioria dos profissionais intérpretes atuantes não possui formação acadêmica para desempenhar essa função. Os primeiros cursos ecertificados de proficiência ainda estão começando a surgir no Brasil . Entretanto, a contratação desses profissi onais já vem acontecendo e, em consequência, existea escassez desse recurso humano. Assim sendo, pessoas com alguma proficiência em LIBRA S vêm sendo contratadas para esse trabal ho e se capacitando em serviço, na maioria das vezes, sem nenhum tipo de orientação. As instituições têm ficado em situação desconfortável, ao se conscientizarem da necessi dade de contratação dos profissionais intérpretes, mas esbarram na falta do recurso humano e despreparo dos intérpretes, o que podecausar prejuízo ao al uno e sua escolarização (LEITE, 2004).

Já no âmbito curricular, elementos favoráveis e desfavoráveis podem ser, deforma introdutória, pontuados. Depositivo pode-seapontar para o empenho da elaboração de um mapa curricular que rompe com uma série de paradigmas tradicionais. A estrutura transdisciplinar dialoga com o quehá demel hor nas atuais Diretrizes Nacionais para o Curso de Pedagogia e procura de forma produtiva tecer as especificidades do universo da surdez ao longo das disciplinas propostas.

\footnotetext{
${ }^{16}$ Durante a realização deste estudo, verificou-se um movimento organizado entre os surdos do terceiro período do curso. Eles senegaram a assistir às aulas com intérpretes atuando deforma precária, seja pela dificuldade de interpretação em si, seja pel o fato de que éfreqüente a presença de apenas um intérprete em sala, quando o correto seria o revezamento entre pares.
} 
A idéia deutilizar a carga das atividades complementares como Tópicos deEducação Bilíngue como um espaço de oficina de Libras ou projetos de Pesquisa eExtensão dessa natureza, foi a solução encontrada para a existência de um " lugar" onde a LIBRAS pudesse ser aprendida, já que no Projeto do N ormal Superior esse espaço não existia, na medida em que se partia do pressuposto de que o curso era bilíngue e que, portanto, a aquisição e proficiência da língua de sinais já estaria dada.Enfim, esta é uma questão que também precisa ser equacionada.

Ainda no corpo do mapeamento curricular quejá está sendo praticado, vale observar al gumas outras contradições. As disci plinas de Língua Portuguesa, por exemplo, têm como objetivo ensinar português escrito como L2, uma vez quea L1 ou língua de instrução é a LIBRAS. No entanto, não há como considerar que processos deensino-aprendizagem comuns desurdos, quetêm a língua portuguesa como L2 e ouvintes que têm a língua portuguesa como L1.

\section{Conclusão}

Como se organiza um curso superior bilíngue? Sabe-se que em escolas bilíngues tradicionais a instrução é toda mi nistrada na primeira língua, cabendo à segunda língua o espaço de língua estrangeira. Esta éuma real idadefactível deser implantada no INES, levando-se em consideração que nos seus 150 anos possui precariamente esses serviços no âmbito de seu Colégio de A plicação? Em que se distingue um ensino bilíngue para ouvintes do ensino bilíngue que reúne surdo e ouvintenuma mesma sala deaula, com professores ouvintes trabal hando mediados por intérpretes? Em médio ou longo prazo é possível pensar num fechamento de ciclo em que o próprio curso fosse capaz de formar surdos, aptos a concorrer em futuros concursos para compor o corpo docente?

Por outro lado, no mínimo dois aspectos importantes devem ser considerados à guisa de reflexões finais.

Um curso não podeseconsiderar bilínguetendo a L1 utilizada deforma precária por ouvintes. E essa precariedade não se resolve apenas por meio de intérpretes, mesmo queestes tenham formação adequada. A lém da efetiva utilização da L1 como língua de instrução, um curso bilíngue dessa natureza não pode prescindir de pensar estratégias teórico-práticas, que identifiquem processos específicos da educação de surdos, ainda que no âmbito superior. Esse aspecto remete ao segundo aspecto importante a ser considerado. O projeto políticopedagógico desenvolvido por uma pequena equipe para consolidar a autorização defuncionamento do curso precisa ser praticado, criticado, elogiado. Os envolvidos nesse processo - surdos, ouvintes professores, coordenadores - precisam estabelecer um diálogo acadêmico que promova diretrizes propositivas com vistas à atualização constante do currículo. Ou seja, o curso que agora se inicia tem a tarefa desubmeter seus pressupostos à realidade escolar e a seus agentes principais - dirigentes, professores, alunos e familiares - de modo que um projeto político-pedagógico possa ser urdido a muitas mãos, como deve ser o espírito da política. 
Além disso, administração do ISBE precisa desenvolver estudos de demandas dos profissionais necessários ao funcionamento do curso, bem como proporcionar queos docentes vinculados por força delei ao ensino superior federal venham criar regras internas de funcionamento, tanto de progressão funcional, quanto de al ocação das cargas de trabal ho. Esteé o caminho para viabilizar que se realizem, além da sala deaula, estudos epesquisas, projetos deextensão, elementos fundamentais para que o Instituto não seconstitua, apenas, num grande "escolão", contraditoriamente, muito pouco bilíngue, desperdiçando o frutífero campo que agora se abre à investigação.

Ou seja, há muito a fazer. Traçar novos planos e buscar corrigir falhas que possam comprometer o compromi sso firmado entre o M inistério da Educação, o INES, a comunidade surda e todos aqueles que direcionaram seus anseios profissionais eafetivos na luta por uma mel horia nas condições de oferta do ensino de surdos no Brasil, em todos os níveis.

Tudo leva a crer que uma política cultural bilíngue está sendo urdida no Brasil, de forma inédita, configurando-se numa abertura a uma nova lógica, a um novo e comprometido sentido da prática histórica como prática política e, sobretudo, “um ensaio à liberdade".

\section{Referências}

ARENDT, H. O que é Política? fragmentos das Obras Póstumas compilados por Ursula Ludz. Rio de Janeiro: Editora Bertrand Brasil, 2006.

BRA SIL. CORDE. Câmara Técnica. 0 surdo ea Língua de Sinais. Brasília: Ministério da Justiça/ Secretaria dos Direitos da Cidadania/ CORDE, 2006.

LEITE, E. M. Os papéis do intérprete na sala de aula inclusiva. 2004. Dissertação (Mestrado em Linguística A plicada) - Universi dade Federal do Rio de Janeiro, Rio de Janeiro, 2004.

QUADROS, R. M. Políticas lingüísticas: o impacto do Decreto 5.626 para os surdos brasileiros. Espaço - Informativo Técnico Científico do INES, n. 25/ 26, p 15-25, 2006.

ROCHA, S. Histórico do INES. In: Espaço - Informativo Técnico-Científico do INES. Edição Especial, 2006.

SKLIAR, C. A localização política da educação bilíngüe para surdos. In: A tualidade da Educação Bilíngüe. Porto Alegre: Editora Mediação, 1999. p. 07-14.

SOBREIRA, H; CICON NE, M. FRAN CO, M. Projeto do Curso Bilíngüe de Pedagogia, dez. 2006. Mimeo.

SOUZA, R. M. Situação Bilíngüe Nacional: os cidadãos surdos. SEMINÁRIO SURDEZ, CIDADA NIA E EDUCAÇÃ O: refletindo sobre os processos de exclusão e inclusão. A nais... Rio de Janeiro: INES, DIESP, 1998, p. 36-45. 


\section{A nexo A: Mapeamento curricular normal superior do ines}

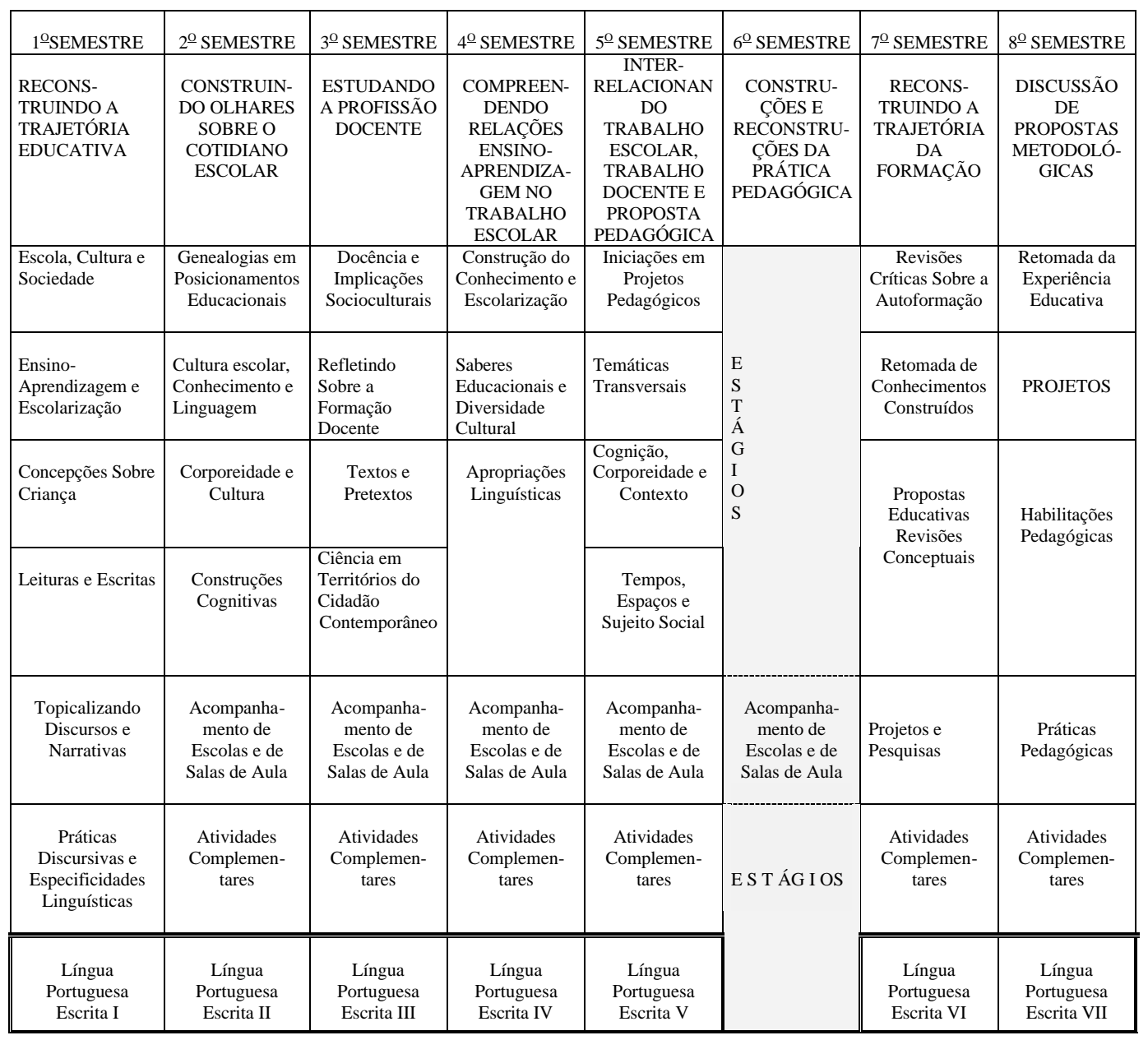




\section{A nexo B - Mapeamento curricular para o curso bilíngue de pedagogia do ines}

\begin{tabular}{|c|c|c|c|c|c|c|c|}
\hline $1^{\circ}$ SEMESTRE & $2^{\circ}$ SEMESTRE & $3^{\circ}$ SEMESTRE & $4^{\circ}$ SEMESTRE & $5^{\circ}$ SEMESTRE & $6^{\circ}$ SEMESTRE & $7^{\circ}$ SEMESTRE & $8^{\circ}$ SEMESTRE \\
\hline $\begin{array}{c}\text { RECONS- } \\
\text { TRUINDO A } \\
\text { TRAJETÓRIA } \\
\text { EDUCATIVA }\end{array}$ & $\begin{array}{l}\text { CONSTRUIN- } \\
\text { DO OLHARES } \\
\text { SOBRE O } \\
\text { COTIDIANO } \\
\text { ESCOLAR }\end{array}$ & $\begin{array}{c}\text { PROBLEMÁ- } \\
\text { TICAS } \\
\text { COTIDIANAS } \\
\text { DA PROFISSÃ̃ } \\
\text { DOCENTE }\end{array}$ & $\begin{array}{c}\text { APROFUN- } \\
\text { DANDO } \\
\text { RELAÇÕES } \\
\text { ENSINO-- } \\
\text { APRENDIZAGEM } \\
\text { NO TRABALHO } \\
\text { PEDAGÓGICO }\end{array}$ & $\begin{array}{c}\text { REDESE- } \\
\text { NHANDO } \\
\text { ENTENDI- } \\
\text { MENTOS } \\
\text { EDUCATIVOS }\end{array}$ & $\begin{array}{l}\text { DELINEANDO } \\
\text { PROPOSTAS } \\
\text { METODOLÓ- } \\
\text { GICAS }\end{array}$ & $\begin{array}{c}\text { RECONS- } \\
\text { TRUINDO A } \\
\text { TRAJETÓRIA } \\
\text { DA } \\
\text { FORMAÇÃO }\end{array}$ & $\begin{array}{l}\text { REDISCUTIN- } \\
\text { DO } \\
\text { PROPOSTAS } \\
\text { EDUCATIVAS } \\
\text { E METODO- } \\
\text { LÓGICAS }\end{array}$ \\
\hline $\begin{array}{l}\text { Escola, Cultura } \\
\text { e Sociedade } \\
80 \mathrm{~h}\end{array}$ & $\begin{array}{c}\text { Genealogias em } \\
\text { Posicionamentos } \\
\text { Educacionais } \\
\mathbf{8 0 h}\end{array}$ & $\begin{array}{c}\text { Docência e } \\
\text { Implicações } \\
\text { Socioculturais } \\
\mathbf{8 0 h}\end{array}$ & $\begin{array}{c}\text { Construção do } \\
\text { Conhecimento e } \\
\text { Escolarização } \\
80 \mathrm{~h}\end{array}$ & $\begin{array}{c}\text { Saberes } \\
\text { Educacionais, } \\
\text { Diversidade } \\
\text { Cultural e } \\
\text { Docência } \\
\mathbf{8 0 h}\end{array}$ & $\begin{array}{c}\text { Ensino da } \\
\text { Educação Física } \\
\text { - tendências } \\
\text { atuais } \\
\mathbf{8 0 h}\end{array}$ & $\begin{array}{c}\text { Revisões } \\
\text { Críticas Sobre a } \\
\text { Autoformação } \\
\text { 80h }\end{array}$ & $\begin{array}{l}\text { Retomada da } \\
\text { Experiência } \\
\text { Educativa } \\
80 \mathrm{~h}\end{array}$ \\
\hline $\begin{array}{c}\text { Ensino- } \\
\text { Aprendizagem e } \\
\text { Escolarização } \\
80 \mathrm{~h}\end{array}$ & $\begin{array}{c}\text { Cultura Escolar, } \\
\text { Conhecimento e } \\
\text { Linguagem } \\
80 \mathrm{~h}\end{array}$ & $\begin{array}{l}\text { Refletindo } \\
\text { Sobre a } \\
\text { Formação } \\
\text { Docente } \\
80 \mathrm{~h}\end{array}$ & $\begin{array}{c}\text { Saberes } \\
\text { Educacionais e } \\
\text { Diversidade } \\
\text { Cultural } \\
80 \mathrm{~h}\end{array}$ & $\begin{array}{c}\text { Cognição, } \\
\text { Corporeidade e } \\
\text { Contexto } \\
80 \mathrm{~h}\end{array}$ & $\begin{array}{c}\text { Tempos- } \\
\text { Espacose } \\
\text { Sujeito Social } \\
\text { em Currículos } \\
\text { de História e } \\
\text { Geografia } \\
\mathbf{8 0 h}\end{array}$ & $\begin{array}{c}\text { Retomada de } \\
\text { Conhecimentos } \\
\text { Construídos } \\
80 \mathrm{~h}\end{array}$ & $\begin{array}{l}\text { Educação e sua } \\
\text { Gestão - metas }\end{array}$ \\
\hline $\begin{array}{l}\text { Concepções } \\
\text { Sobre } \\
\text { Criança } \\
\mathbf{8 0 h}\end{array}$ & \multirow[t]{2}{*}{$\begin{array}{c}\text { Corporeidade e } \\
\text { Cultura } \\
80 \mathrm{~h}\end{array}$} & $\begin{array}{l}\text { A Escola como } \\
\text { Espaço Político- } \\
\text { Pedagógico } \\
80 \mathrm{~h}\end{array}$ & \multirow[t]{2}{*}{$\begin{array}{l}\text { Apropriações } \\
\text { Linguísticas } \\
120 \mathrm{~h}\end{array}$} & \multirow{2}{*}{$\begin{array}{l}\text { Textos e } \\
\text { Pretextos } \\
\text { 80h }\end{array}$} & $\begin{array}{c}\text { Ciência e } \\
\text { Territórios do } \\
\text { Cidadão } \\
\text { Contemporâneo } \\
\mathbf{8 0 h}\end{array}$ & $\begin{array}{c}\text { Propostas } \\
\text { Educativas- } \\
\text { Revisões } \\
\text { Conceptuais }\end{array}$ & \\
\hline $\begin{array}{l}\text { Leituras e } \\
\text { Escritas } \\
54 \mathrm{~h}\end{array}$ & & \multirow{2}{*}{$\begin{array}{c}\text { Construção } \\
\text { Compartilhada } \\
\text { do } \\
\text { Conhecimento } \\
\text { Escolar } \\
80 \mathrm{~h}\end{array}$} & & & $\begin{array}{c}\text { Construções } \\
\text { Cognitivas e } \\
\text { Ensino da } \\
\text { Matemática } \\
\text { 80h }\end{array}$ & & $\begin{array}{c}\text { Consecução } \\
\text { Supervisionada } \\
\text { de Trabalho } \\
\text { Monográfico II } \\
\text { 80h }\end{array}$ \\
\hline \multirow{2}{*}{$\begin{array}{c}\text { Topicalizando } \\
\text { Discursos e } \\
\text { Narrativas } \\
80 \mathrm{~h}\end{array}$} & \multirow{2}{*}{$\begin{array}{l}\text { Construções } \\
\text { Cognitivas } \\
80 \mathrm{~h}\end{array}$} & & $\begin{array}{c}\text { Tempos, } \\
\text { Espaços e } \\
\text { Sujeito Social } \\
\quad 80 \mathrm{~h}\end{array}$ & $\begin{array}{l}\text { Temáticas } \\
\text { Transversais } \\
80 \mathrm{~h}\end{array}$ & \multirow{2}{*}{$\begin{array}{l}\text { Leituras e } \\
\text { Escritas e } \\
\text { Diversidades } \\
\text { Linguísticas } \\
\mathbf{8 0 h}\end{array}$} & $\begin{array}{c}\text { Consecução } \\
\text { Supervisionada } \\
\text { de Trabalho } \\
\text { Monográfico I } \\
\mathbf{8 0 h}\end{array}$ & $\begin{array}{l}\text { Práticas } \\
\text { Pedagógicas } \\
\quad 80 \mathrm{~h}\end{array}$ \\
\hline & & $\begin{array}{l}\text { Corporeidade, } \\
\text { Cultura e } \\
\text { Discurso } \\
120 \mathrm{~h}\end{array}$ & $\begin{array}{l}\text { Arte em } \\
\text { Processo na } \\
\text { Escola } \\
80 \mathrm{~h}\end{array}$ & $\begin{array}{c}\text { ESTÁGIO } \\
\text { SUPERVI- } \\
\text { SIONADO I } \\
\quad 60 \mathrm{~h}\end{array}$ & & $\begin{array}{c}\text { ESTÁGIO } \\
\text { SUPERVI- } \\
\text { SIONADO III } \\
130 \mathrm{~h}\end{array}$ & $\begin{array}{c}\text { ESTÁGIO } \\
\text { SUPERVI- } \\
\text { SIONADO IV } \\
130 \mathrm{~h}\end{array}$ \\
\hline $\begin{array}{c}\text { Práticas } \\
\text { Discursivas e } \\
\text { Especificidades } \\
\text { Linguísticas } \\
\mathbf{8 0 h}\end{array}$ & $\begin{array}{c}\text { Tópicos } \\
\text { Avançados de } \\
\text { Âmbito Bilíngue } \\
\mathbf{8 0 h}\end{array}$ & $\begin{array}{c}\text { Tópicos } \\
\text { Avançados de } \\
\text { Âmbito Bilíngue } \\
80 \mathrm{~h}\end{array}$ & $\begin{array}{c}\text { Tópicos } \\
\text { Avançados de } \\
\text { Âmbito Bilíngue } \\
\mathbf{8 0 h}\end{array}$ & $\begin{array}{c}\text { Tópicos } \\
\text { Avançados de } \\
\text { Âmbito Bilíngue } \\
80 \mathrm{~h}\end{array}$ & $\begin{array}{c}\text { ESTÁGIO } \\
\text { SUPERVI- } \\
\text { SIONADO II } \\
\quad 60 \mathrm{~h}\end{array}$ & $\begin{array}{c}\text { Tópicos } \\
\text { Avançados de } \\
\text { Âmbito Bilíngue } \\
\mathbf{8 0 h}\end{array}$ & $\begin{array}{c}\text { Tópicos } \\
\text { Avançados de } \\
\text { Âmbito Bilíngue } \\
\mathbf{8 0 h}\end{array}$ \\
\hline $\begin{array}{c}\text { Língua } \\
\text { Portuguesa } \\
\text { Escrita I } \\
120 h\end{array}$ & $\begin{array}{c}\text { Língua } \\
\text { Portuguesa } \\
\text { Escrita II } \\
80 \mathrm{~h}\end{array}$ & $\begin{array}{c}\text { Língua } \\
\text { Portuguesa } \\
\text { Escrita III } \\
80 \mathrm{~h}\end{array}$ & $\begin{array}{c}\text { Língua } \\
\text { Portuguesa } \\
\text { Escrita IV } \\
80 \mathrm{~h}\end{array}$ & $\begin{array}{c}\text { Língua } \\
\text { Portuguesa } \\
\text { Escrita V } \\
80 \mathrm{~h}\end{array}$ & $\begin{array}{c}\text { Tópicos } \\
\text { Avançados de } \\
\text { Âmbito Bilíngue } \\
\text { 80h }\end{array}$ & $\begin{array}{c}\text { Língua } \\
\text { Portuguesa } \\
\text { Escrita VI } \\
\mathbf{8 0 h}\end{array}$ & $\begin{array}{c}\text { Língua } \\
\text { Portuguesa } \\
\text { Escrita VII } \\
\quad 80 \mathrm{~h}\end{array}$ \\
\hline
\end{tabular}

Eixos Norteadores em espaço incolor; Núcleo de Estudos Básicos em cinza médio; Núcleo de A profundamento e Diversificação de Estudos em cinza escuro; Núcl eo de Estudos Integradores em cinza mais claro.

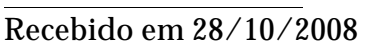

A provado em 20/ 03/ 2009 